\title{
Adenoma of the ampulla of Vater: a case report
}

\author{
Konstantinos Alexiou, Argyrios loannidis", loannis Drikos, Athanasios Fotopoulos, loannis Karanikas \\ and Nikolaos Economou
}

\begin{abstract}
Introduction: Lesions of the ampulla of Vater are rare histological entities with an incidence of between 0.1 and $0.2 \%$ of gastrointestinal tumors. Until recently the main response to this kind of lesion was duodenopancreatectomy, regardless of the cellular atypia and local edema. In this study, we propose the application of transduodenal local excision of the ampulla of Vater especially in recognized cases of nonmalignant adenomas.
\end{abstract}

Case presentation: In this case report we analyze the case of a 78-year-old Greek man who revealed symptoms such as icterus, abdominal pain without constipation and bloody stools. A physical examination showed painless swelling of the gallbladder (Courvoisier sign). No previous abdominal operations or hernias were identified. Blood tests, computed tomography scan analysis, gastroscopy and endoscopic retrograde cholangiopancreatography along with biopsies and cytological tests diagnosed nonmalignant adenoma of the ampulla of Vater with high-grade dysplasia. The treatment we followed was transduodenal local excision of his ampulla of Vater.

Conclusions: Transduodenal local excision of the ampulla of Vater has limited side effects and postoperative complications, suggesting this particular technique to be the proper treatment for nonmalignant cases of adenomas.

Keywords: Adenoma of ampulla of Vater, Transduodenal excision

\section{Introduction}

Adenoma of the ampulla of Vater is a difficult-to-diagnose cause of obstruction of the biliary duct. It is among the rarest of gastrointestinal neoplasms. It is usually identified after gastroscopy followed by biopsies but often gets misdiagnosed. It carries a significant rate of morbidity and mortality.

\section{Case presentation}

In this study we present a case of a 78-year-old Greek man who was diagnosed with adenoma of the ampulla of Vater. He presented in the emergency room with symptoms of abdominal pain without constipation and bloody stools. A physical examination showed icterus and Courvoisier sign.

The laboratory findings were: total bilirubin, $2.63 \mathrm{mg} / \mathrm{dL}$ (normal 0.3 to 1.5 ); direct bilirubin, $1.33 \mathrm{mg} / \mathrm{dL}$ (normal 0.01 to 0.35 ); indirect bilirubin, $1.50 \mathrm{mg} / \mathrm{dL}$ (normal 0.01 to 0.35 ); serum albumin, $3.14 \mathrm{~g} / \mathrm{dL}$ (normal 3.5 to 5.0 ); alanine aminotransferase, 24U/L (normal 0 to 50); aspartate aminotransferase, 34U/L (normal 0 to 40 ); c-glutamyl

\footnotetext{
* Correspondence: argioannid@med.uoa.gr

Department of Surgery, Sismanoglion General Hospital, Sismanoglou 1, P.O. Box 15126, Athens, Greece
}

transpeptidase, 27U/L (normal 0 to 40); alkaline phosphatase, 136IU/L (normal 30 to 140); C-reactive protein $221 \mathrm{mg} / \mathrm{dL}$ (normal 0 to 10 ); white blood cell $8300 / \mu \mathrm{L}$ (normal 4000 to 10000); creatinine kinase 191U/L (24 to 195IU/L); carbohydrate antigen 19-9, 50.2U/mL (normal 0 to 37 ); cancer antigen $15-3,45.2 \mathrm{U} / \mathrm{mL}$ (normal 0 to 30 ).

Ultrasonography of his abdomen revealed cholelithiasis and dilated intrahepatic and outer hepatic bile vessels. A computed tomography (CT) scan analysis showed a mass in his ampulla of Vater and pancreas, and revealed multiple calcified elements compatible with chronic pancreatitis (Figure 1). Lithiasis of his bile duct was also present. Magnetic resonance imaging (MRI) could not be done because of his pacemaker.

Five days later endoscopic retrograde cholangiopancreatography (ERCP) was conducted. Entrance through the ampulla of Vater was impossible but a biopsy was taken for cytological examination. The histological analysis showed nonmalignant disease.

Two days later common biopsies were taken during a gastroscopy (Figure 2) process and the results revealed nonmalignant papillary adenoma with high-grade dysplasia.

Considering the size, the position and absence of malignancy we decided to proceed to transduodenal local 


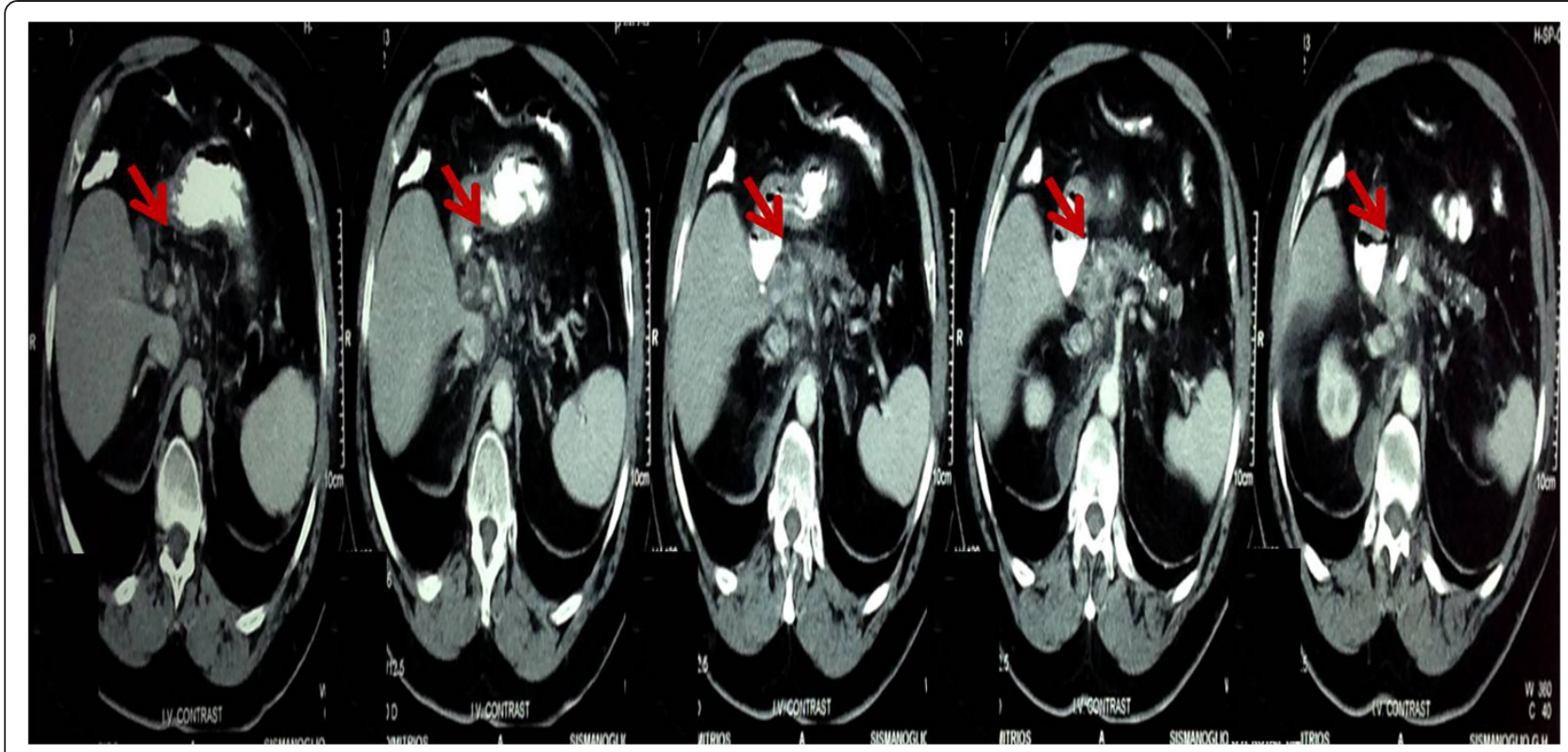

Figure 1 The abdominal computed tomography showed a mass at the ampulla of Vater (arrows).

excision of the adenoma. The operation consisted of transduodenal local excision of the adenoma of the ampulla of Vater, sphincterotomy of Oddi, followed by Oddi sphincteroplasty, exploration of his common bile duct and gastrointestinal anastomosis. Finally a Kehr tube was placed in his common bile duct through the incision of the exploration. The gastrointestinal anastomosis was conducted to reduce the inner pressure at his duodenum.

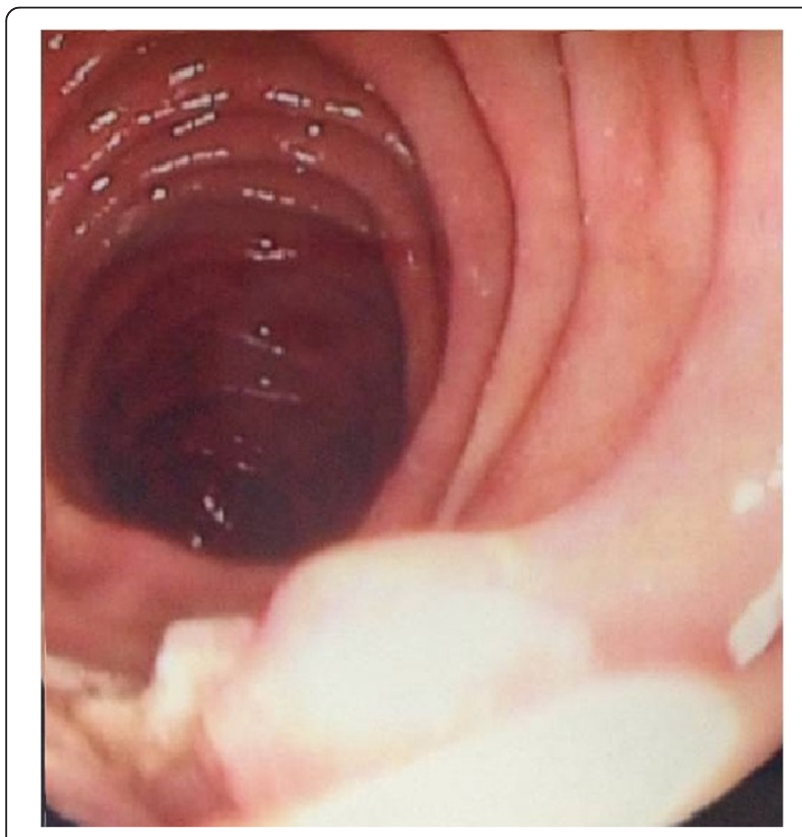

Figure 2 Gastroduodenal endoscopy showed a swollen duodenal adenoma of the ampulla of Vater with white mucosal covering.
The length of the procedure was 2 hours and 13 minutes and the estimated blood loss was approximately $280 \mathrm{~mL}$. Transfusion was not necessary as the his postoperative hematocrit was $35 \%$.

One week later a postoperative cholangiography (Figure 3) revealed no obstructions of his biliary tree and the results of his biochemical blood tests were normal.

The final histological examination verified the biopsies from the gastroscopy. More specifically, the excision specimen consisted of mucosal and submucosal regions of his duodenum; it showed papillary adenoma with high-grade dysplasia, nonspecific inflammation and local corrosions, without evidence of malignancy (Figure 4).

He was discharged after a total of 16 days in our hospital.

\section{Discussion}

Lesions of the ampulla of Vater are rare histological entities that in most cases have a high potential for malignancy [1]. Until recently, the main response to this kind of lesion was duodenopancreatectomy, regardless of the histological type, malignancy and local edema. However, improvements in diagnosis and therapy demonstrate the proper operation to be endoscopic removal of the adenoma when the tumor is detected. When endoscopic treatment is not possible, ampullectomy is an important technique compared with duodenopancreatectomy [1,2].

Adenoma of the ampulla of Vater was first described in 1895 by Calzavara [3] and diagnosis was difficult until 1973 when it became possible to implement ERCP in diagnosis of the biliary tree and pancreatic malformations. Adenomas of the ampulla of Vater are rare neoplasms that occur sporadically or in the context of genetic syndromes 


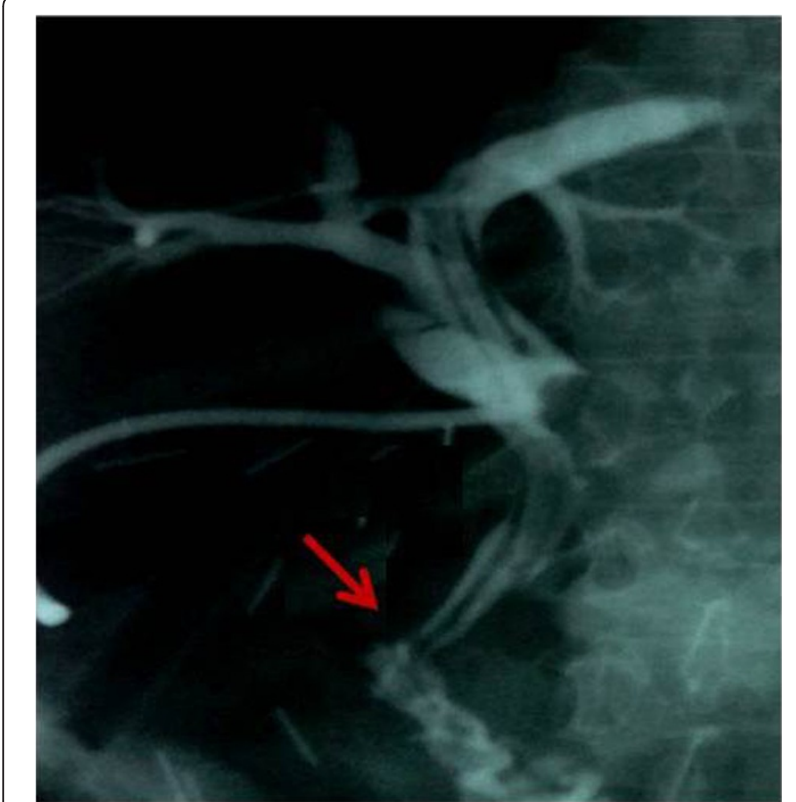

Figure 3 The postoperative cholangiography reveals common bile and pancreatic duct able to drain into the duodenum. The arrow indicates the pancreatic duct.

such as familial adenomatous polyposis and sometimes turn into malignant adenocarcinomas $[4,5]$. In terms of histopathological classification of neoplasmatic lesions of the ampulla of Vater, $40 \%$ are tubulovillous adenomas, $30 \%$ villous adenomas, $10 \%$ tubular adenomas and $20 \%$ are nonepithelial lesions such as endocrine adenomas or neurinomas. In addition, neoplasmatic lesions of the ampulla of Vater were found to range from 0.063 to $0.21 \%[6,7]$.

Tumors of the ampulla of Vater are usually identified by gastroscopy or ERCP. ERCP and endoscopic ultrasonography

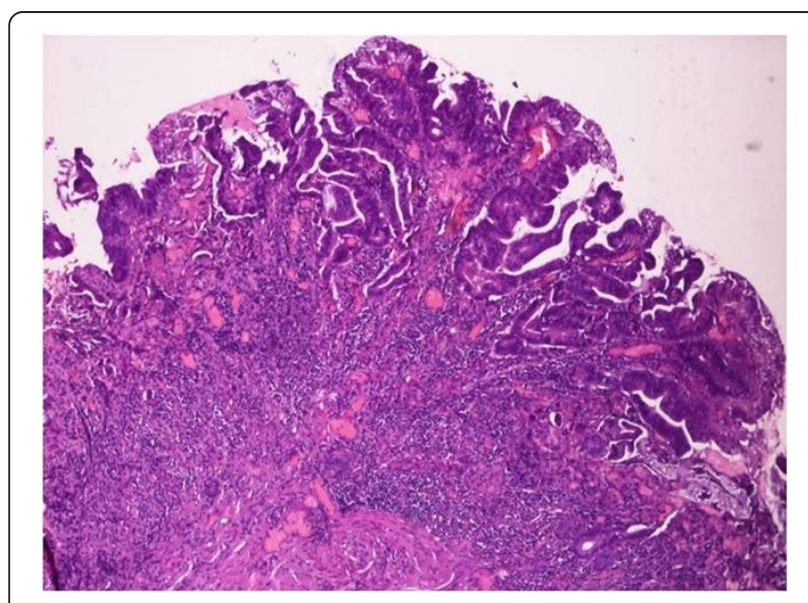

Figure 4 The histological analysis of the sample of the ampulla of Vater reveals adenoma with high-grade dysplasia and nonspecific inflammation with local corrosions. provide important information for the assessment of adenomas. With these techniques we can properly assess the intraductal extension of the tumor, demonstrating the best possible staging of the tumor toward the CT, the MRI and transabdominal ultrasound [8]. With the implementation of the evaluation of ERCP, the evaluation of adenomas is more accurate and intraduodenal surgical excision has become the proper treatment.

Furthermore, once adenomas of the ampulla of Vater have been identified they may be treated by surgical excision [8,9] and in patients with advanced size and cellular atypia, the surgical resection of adenoma seems to be the proper treatment option [10]. Although many patients reveal side effects after curative resection [11], most cases exhibit limited complications. The main complications include pancreatitis, postoperative bleeding and biliary tree inflammation [11].

Apart from intraduodenal resection of the ampulla of Vater, a pancreaticoduodenectomy may be used for the resection. This technique was first implemented in 1935 by Whipple et al. [12] and applied in a patient with carcinoma of the ampulla of Vater. In this study, the patient died after 25 months because of liver metastasis. This technique may be applied in cases of papillary adenocarcinoma and high-grade dysplasia. By contrast, Hoyuela et al. [13] reported a research study with four patients with adenomas of the ampulla of Vater who had a Whipple operation and showed no evidence of disease recurrence. The major advantages of the Whipple operation are the reduced risk of recurrence and the exclusion of sporadic adenomas presented in the ampulla of Vater. However, the technique has significant drawbacks mainly increased postoperative mortality and morbidity.

A research study conducting pancreaticoduodenectomies for Vater adenomas showed a mortality rate of up to $10 \%$ and morbidity rate from $25 \%$ to $65 \%$ [14]. In recent years the morbidity and mortality rates have improved but the longer hospitalizations have increased the cost of hospital care and possibly change quality of life $[14,15]$.

In addition, patients with aggressive carcinoma of the ampulla of Vater who were treated with local excision, showed a high rate of recurrence after application of transduodenal local excision and a low rate of recurrence after Whipple surgery $[15,16]$, suggesting that the application of transduodenal local excision is recommended when benign tumors are detected by histological analysis, as in our case.

Scientific data have already shown that the mortality rate $(<1 \%)$ and the hospitalization time are lower after local ablation of adenomas of the ampulla of Vater. The advantages are also the lack of conducting a laparotomy and the necessity of general anesthesia [16-18], with the proviso that the patient be subject to regular postoperative 
monitoring in order to determine the risk of recurrence. Side effects such as pancreatitis and bleeding after transduodenal local excision seem to be self-limited and usually affected no more than $10 \%$ of patients. The temporary drainage of the pancreatic duct by using stents such as in our case may reduce postoperative acute pancreatitis.

\section{Conclusions}

Adenoma of the ampulla of Vater is a rare nonmalignant tumor that cannot be diagnosed easily and carries significant rates of mortality and morbidity. Our therapeutic approach was selected in order to avoid postoperative complications such as those that might occur with duodenopancreatectomy. Even if endoscopic ampullectomy has been tried in some progressive institutions, further research to compare those two methods needs to be carried out in order to identify the proper therapy in cases of nonmalignant adenomas of the ampulla of Vater.

\section{Consent}

Written informed consent was obtained from the patient for publication of this case report and any accompanying images. A copy of the written consent is available for review by the Editor-in-Chief of this journal.

\section{Abbreviations}

CT: Computed tomography; ERCP: Endoscopic retrograde

cholangiopancreatography; MRI: Magnetic resonance imaging.

\section{Competing interests}

The authors declare that they have no competing interests.

\section{Authors' contributions}

$K A, A I, I D, A F, I K$, and NE carried out and participated at the surgical excision and the manuscript demonstration. KA, Al, and ID participated in the design of the study and helped to draft the manuscript. All authors read and approved the final manuscript.

\section{Acknowledgements}

We would like to thank the consultants of the Department of Surgery, Sismanoglion General Hospital Athens, for kindly allowing the patient to be included in the study.

Received: 27 November 2013 Accepted: 14 April 2014

Published: 25 June 2014

\section{References}

1. Beger HG, Treitschke F, Gansauge F, Harada N, Hiki N, Mattfeldt T: Tumor of the ampulla of Vater: experience with local or radical resection in 171 consecutively treated patients. Arch Surg 1999, 134(5):526-532.

2. Sastre B, Ouaissi M, Chaix JB, Pirro N, Cosentino B, Sielezneff I: Resection of the ampulla of Vater. J Chir (Paris) 2006, 43:246-250.

3. Calzavara C: Uber adenome des Verdanungskanals. Wirchows Arch (A) $1895,141: 221$

4. Morpurgo E, Vitale GC, Galandiuk S, Kimberling J, Ziegler C, Polk HC Jr: Clinical characteristics of familial adenomatous polyposis and management of duodenal adenomas. J Gastrointest Surg 2004, 8:559-564

5. Ouaïssi M, Panis Y, Sielezneff I, Alves A, Pirrò N, Robitail S, Heyries L, Valleur $P$, Sastre B: Long-term outcome after ampullectomy for ampullary lesions associated with familial adenomatous polyposis. Dis Colon Rectum 2005, 48:2192-2196

6. Perzin KH, Bridge MF: Adenomas of the small intestine: a clinicopathologic review of 51 cases and a study of their relationship to carcinoma. Cancer 1981, 48(3):799-819.
7. Yamaguchi K, Enjoji M: Carcinoma of the ampulla of Vater. A clinicopathologic study and pathologic staging of 109 cases of carcinoma and 5 cases of adenoma. Cancer 1987, 59(3):506-515.

8. Chen CH, Tseng LJ, Yang CC, Yeh YH, Mo LR: The accuracy of endoscopic ultrasound, endoscopic retrograde cholangiopancreatography, computed tomography, and transabdominal ultrasound in the detection and staging of primary ampullary tumours. Hepatogastroenterology 2001, 48:1750-1753.

9. Yoon YS, Kim SW, Park SJ, Lee HS, Jang JY, Choi MG, Kim WH, Lee KU, Park YH: Clinicopathologic analysis of early ampullary cancers with a focus on the feasibility of ampullectomy. Ann Surg 2005, 242:92-100.

10. Posner S, Colletti L, Knol J, Mulholland M, Eckhauser F: Safety and longterm efficacy of transduodenal excision for tumours of the ampulla of Vater. Surgery 2000, 128:694-701.

11. Zhong J, Palta M, Willett CG, McCall SJ, Bulusu A, Tyler DS, White RR, Uronis HE, Pappas TN, Czito BG: The role of local excision in invasive adenocarcinoma of the ampulla of Vater. J Gastrointest Oncol 2013, 4(1):8-13.

12. Whipple AO, Parsons WB, Mullins CR: Treatment of the carcinoma of the ampulla of Vater. Ann Surg 1935, 102(4):763-779.

13. Hoyuela C, Cugat E, Veloso E, Marco C: Treatment options for villous adenoma of the ampulla of Vater. HPB Surg 2000, 11(5):325-330.

14. Martin JA, Haber GB: Ampullary adenoma: clinical manifestations, diagnosis, and treatment. Gastrointest Endosc Clin N Am 2003, 13(4):649-669.

15. Bohra AK, McKie L, Diamond T: Transduodenal excision of ampullary tumours. Ulster Med J 2002, 71:121-127.

16. Schoenberg MH, Treitschke F, Harada N, Beger HG: Benign tumour of the ampulla of Vater: surgical treatment and prognosis. Eur J Surg 1998, 164:765-770.

17. Dixon E, Vollmer CM, Sahajpal A, Cattral MS, Grant DR, Taylor BR, Langer B, Gallinger S, Greig PD: Transduodenal resection of peri-ampullary lesions. World J Surg 2005, 29:649-652.

18. Ceppa EP, Burbridge RA, Rialon KL, Omotosho PA, Emick D, Jowell PS, Branch MS, Pappas TN: Endoscopic versus surgical ampullectomy: an algorithm to treat disease of the ampulla of Vater. Ann Surg 2013, 257:315-322.

doi:10.1186/1752-1947-8-228

Cite this article as: Alexiou et al:: Adenoma of the ampulla of Vater: a case report. Journal of Medical Case Reports 2014 8:228.

\section{Submit your next manuscript to BioMed Central and take full advantage of:}

- Convenient online submission

- Thorough peer review

- No space constraints or color figure charges

- Immediate publication on acceptance

- Inclusion in PubMed, CAS, Scopus and Google Scholar

- Research which is freely available for redistribution 